\title{
Inventory Model with Quadratic Demand under the Two Warehouse Management System
}

\author{
A K Malik ${ }^{1}$, Dipak Chakraborty², Kapil Kumar Bansal ${ }^{3}$ and ${ }^{*}$ Satish Kumar ${ }^{4}$ \\ ${ }^{1}$ Associate Professor, Department of Mathematics, \\ B.K. Birla Institute of Engineering \&Technology, Pilani, Rajasthan, India \\ ajendermalik@gmail.com \\ ${ }^{2}$ Research Scholar, Department of Mathematics, \\ Singhania University Pacheri badi, Jhunjhunu Rajasthan, India \\ dipakchakraborty1963@gmail.com \\ ${ }^{3}$ Head, Research \& Publication, SRM University, NCR Campus, Modinagar \\ drkapilbansal25@gmail.com \\ ${ }^{4}$ Associate Professor, Department of Mathematics, D.N. (PG) College, Meerut, U.P. \\ skg22967@gmail.com \\ *Corresponding author: skg22967@gmail.com
}

\begin{abstract}
The objective of this manuscript is to develop an mathematical model for two warehouses. Here we assume two warehouses system, one is Own Warehouse (OW) and other is Rent Warehouse (RW); due to seasonal product for storing the raw material/products. The proposed study is meant for a quadratic demand and variable holding costs in which shortages are not allowed. The solution obtained by the proposed approach, illustrative an example for the optimum total inventory cost and optimum inventory level.
\end{abstract}

Keywords: Quadratic demand, OW and RW, Variable holding and deterioration.

\section{INTRODUCTION}

Motivated by the recent contributions Ghare and Schrader (1963), Covert and Philip (1973) made in the field of the application of inventory models in industries the object of this work will be to investigate the optimum inventory policy and optimum level for the inventory management systems. First Hartely (1976) proposed a techniques for two warehouses inventory management system in which the holding cost of the rent warehouse is larger than the holding cost of the OW. Pakkala and Acharya (1992) presented a method for solving a two warehouse inventory management system for deteriorating items. Apart from that a lot of work has been done to develop Two-warehouses inventory management system with deteriorating items by the researchers like Lee and Ma (2000), Kharna and Chaudhary (2003), Yang (2004), Malik et al. (2008), Niu and Xie (2008), Malik et al. (2008), Lee and Hsu (2009), Singh and Malik (2009a \& b), Sarkar et al. (2010) and others. Singh and Malik (2010) formulated a two storage inventory model with linear deterioration and exponential demand.

Gupta et al. (2010) presents an inventory model with two warehouses and production rate is a function of demand. Singh and Malik (2010) developed a two shops inventory system with variable holding cost. Sana (2010) presented an inventory model with variable deteriorating rate with optimal selling price. Singh et al (2011a \& b) developed a mathematical two warehouse inventory management system. Also, Sett et al (2012) presented a quadratically type demand inventory model with variable deterioration and the two warehouses management system. Kumar et al. (2016) proposed a two warehouse management system with variable demand. Vashisth et al (2016) discussed a two warehouse inventory model with quadratic demand and variable holding cost. Sharma and Bansal (2017) developed an inventory model for non-instantaneous deteriorating items.

Motivated by this idea, in this paper we have presented a quadratic demand with two warehouses inventory model for the deteriorating items. Here we assume two warehouses system with variable deteriorations in the both the warehouses. Holding cost is a function of time and considered; the holding cost of RW is higher than OW. Therefore the total inventory cost of this management system is optimized with a numerical example. 


\section{NOTATION AND ASSUMPTIONS}

Following notations and assumptions are used to developing this model:

1. The Demand $\mathrm{D}(t)=a-b t-c t^{2}$ where $(a, b, c>0)$.

2. The deterioration rates in rent warehouse and own warehouse is $\alpha(t)$ and $\beta(t)$; and defined by $\alpha(t)=\alpha_{1}+\alpha_{2} t$ and $\beta(\mathrm{t})=\beta_{1}+\beta_{2} t$ respectively.

3. The holding costs in rent warehouse and own warehouse is $h(t)$ and $g(t)$; and defined by $h(t)=h_{1}+h_{2} t$ and $g(t)=g_{1}+g_{2} t$ respectively.

4. Shortages are not permitted in this model.

$\mathrm{C}_{\mathrm{O}} \quad$ Ordering cost per order cycle

$\mathrm{S} \quad$ Maximum inventory level in rent warehouse

$\mathrm{N} \quad$ Maximum inventory level in own warehouse

$C_{d} \quad$ Deteriorating cost in both the warehouses per unit

$t_{1} \quad$ Time in which no deterioration occurs

TIC Total inventory cost per unit time

\section{MATHEMATICAL MODEL}

According to above mentioned the notation and assumptions mentioned, $\mathrm{I}_{\mathrm{R}}(\mathrm{t})$ and $\mathrm{I}_{\mathrm{O}}(\mathrm{t})$ are the inventory levels for the rent and own warehouses respectively. The capacities of rent warehouse and own warehouses are $S$ and $\mathrm{N}$ units respectively. In $\left[0, \mathrm{t}_{1}\right]$, the inventory level $\mathrm{I}_{\mathrm{R}}(\mathrm{t})$ decrease due to demand only and at $\mathrm{t}=\mathrm{t}_{1}+\mathrm{t}_{2}$, the inventory level $I_{R}(t)$ becomes zero after satisfying the demand and deterioration. In time period $\left[t_{1}, t_{1}+t_{2}\right]$, the Inventory level $\mathrm{I}_{\mathrm{R}}(\mathrm{t})$ decreases due to both the demand and deterioration but the Inventory level $\mathrm{I}_{\mathrm{O}}(\mathrm{t})$ decreases due to deterioration. In $\left[t_{1}+t_{2}, t_{1}+t_{2}+t_{3}=T\right]$, the Inventory level $I_{0}(t)$ decreases due to both the demand and deterioration and at $\mathrm{t}=\mathrm{T}$, the inventory level $\mathrm{I}_{\mathrm{R}}(\mathrm{t})$ becomes zero after satisfying the demand and deterioration. The following differential equations showing the behavior of inventory levels in rent warehouse and own warehouses:

$$
\begin{aligned}
& \frac{d I_{R}(t)}{d t}=\left\{\begin{array}{cc}
-D(t) & 0 \leq t \leq t_{1} \\
-D(t)-\alpha(t) I_{R}(t) & , t_{1} \leq t \leq\left(t_{1}+t_{2}\right)
\end{array}\right. \\
& \frac{d I_{O}(t)}{d t}=\left\{\begin{array}{cc}
0,0 \leq t \leq t_{1} \\
-\beta(t) I_{O}(t), t_{1} \leq t \leq\left(t_{1}+t_{2}\right) \\
-D(t)-\beta(t) I_{O}(t) & , t_{1}+t_{2} \leq t \leq T
\end{array}\right.
\end{aligned}
$$

With the boundary conditions $I_{R}(0)=S, \quad I_{R}\left(t_{2}\right)=0, \quad I_{O}(0)=N=I_{O}\left(t_{1}\right), \quad I_{O}(T)=0$. The Solution of the above system of equations, we get

$$
\begin{aligned}
& I_{R}(t)=\left\{\begin{array}{lr}
S-a t+\frac{b t^{2}}{2}+\frac{c t^{3}}{3} & 0 \leq t \leq t_{1} \\
\left\{-a\left(t-t_{2}\right)+a_{1}\left(t^{2}-t_{2}^{2}\right)+a_{2}\left(t^{3}-t_{2}^{3}\right)+a_{3}\left(t^{4}-t_{2}^{4}\right)+a_{4}\left(t^{5}-t_{2}^{5}\right)\right\} e^{-\left(\alpha_{1}+\alpha_{2} \frac{t^{2}}{2}\right)} & , t_{1} \leq t \leq\left(t_{1}+t_{2}\right)
\end{array}\right. \\
& I_{O}(t)= \begin{cases}N & , 0 \leq t \leq t_{1} \\
N \cdot e^{\beta_{1}\left(t_{1}-t\right)+\frac{\beta_{2}}{2}\left(t_{1}^{2}-t^{2}\right)} & , t_{1} \leq t \leq\left(t_{1}+t_{2}\right) \\
\left\{-a(t-T)+b_{1}\left(t^{2}-T^{2}\right)+b_{2}\left(t^{3}-T^{3}\right)+b_{3}\left(t^{4}-T^{4}\right)+b_{4}\left(t^{5}-T^{5}\right)\right\} e^{-\left(\beta_{1} t+\beta_{2} \frac{t^{2}}{2}\right)} & , t_{1}+t_{2} \leq t \leq T\end{cases}
\end{aligned}
$$

Where $\quad a_{1}=\frac{b-a \alpha_{1}}{2}, \quad a_{2}=\frac{2 c+2 b \alpha_{1}-a \alpha_{2}}{6}, \quad a_{3}=\frac{2 c \alpha_{1}+b \alpha_{2}}{8}, \quad a_{4}=\frac{c \alpha_{2}}{10}, \quad b_{1}=\frac{b-a \beta_{1}}{2}$, $b_{2}=\frac{2 c+2 b \beta_{1}-a \beta_{2}}{6}, b_{3}=\frac{2 c \beta_{1}+b \beta_{2}}{8}, b_{4}=\frac{c \beta_{2}}{10}$.

Due to continuity of the inventory levels $\mathrm{I}_{\mathrm{R}}(\mathrm{t})$ and $\mathrm{I}_{\mathrm{O}}(\mathrm{t})$, we have

$$
S=a t_{1}+\frac{b t_{1}^{2}}{2}+\frac{c t_{1}^{3}}{3}+\left\{-a\left(t-t_{2}\right)+a_{1}\left(t^{2}-t_{2}^{2}\right)+a_{2}\left(t^{3}-t_{2}^{3}\right)+a_{3}\left(t^{4}-t_{2}^{4}\right)+a_{4}\left(t^{5}-t_{2}^{5}\right)\right\} e^{-\left(\alpha_{1} t+\alpha_{2} \frac{t^{2}}{2}\right)}
$$


and

$$
N=\left\{a t_{3}+b_{1}\left(\left(t_{1}+t_{2}\right)^{2}-T^{2}\right)+b_{2}\left(\left(t_{1}+t_{2}\right)^{3}-T^{3}\right)+b_{3}\left(\left(t_{1}+t_{2}\right)^{4}-T^{4}\right)+b_{4}\left(\left(t_{1}+t_{2}\right)^{5}-T^{5}\right)\right\} e^{-\left(\beta_{1} t_{1}+\beta_{2} \frac{t_{1}^{2}}{2}\right)}
$$

The maximum inventory level is $\mathrm{L}=\mathrm{S}+\mathrm{N}$

Next, the total inventory cost for the developed inventory model per cycle consists of the following elements:

Now the ordering cost for the developed model is denoted as OC and defined is

$$
\mathrm{IOC}=\mathrm{C}_{\mathrm{O}} \text {. }
$$

The Inventory holding cost in Rent Warehouse for the developed model is denoted as $\mathrm{IHC}_{\mathrm{RW}}$ and defined is

$$
I H C_{R W}=\left(\int_{0}^{h_{1}+t_{2}} h(t) I_{R}(t) d t\right)=h_{1} u_{1}(t)-\frac{h_{2} \alpha_{2}}{2} u_{2}(t)-\left(h_{1} \alpha_{1}-h_{2}\right) u_{3}(t)-\left(\frac{h_{1} \alpha_{2}}{2}+\alpha_{1} h_{2}\right) u_{4}(t)+h_{1} u_{5}(t)+h_{2} u_{6}(t)
$$

The Inventory holding cost in Own Warehouse for the developed model is denoted as $\mathrm{IHC}_{\mathrm{OW}}$ and defined is

$$
I H C_{O W}=\left(\int_{0}^{T} g(t) I_{O}(t) d t\right)=g_{1} v_{1}(t)-g_{2} v_{2}(t)-\left(g_{1} \beta_{1}-g_{2}\right) v_{3}(t)-\left(\frac{g_{1} \beta_{2}}{2}+\beta_{1} g_{2}\right) v_{4}(t)+g_{1} v_{5}(t)+g_{2} v_{6}(t)
$$

The deteriorating cost in Rent Warehouse for the developed model is denoted as $\mathrm{DC}_{\mathrm{RW}}$ and defined is

$$
D C_{R W}=C_{d}\left(\int_{t_{1}}^{t_{1}+t_{2}} \alpha(t) I_{R}(t) d t\right)=C_{d}\left(\alpha_{1} u_{1}(t)-\frac{\alpha_{2}^{2}}{2} u_{2}(t)+\left(\alpha_{2}-\alpha_{1}^{2}\right) u_{3}(t)-\frac{3 \alpha_{1} \alpha_{2}}{2} u_{4}(t)\right)
$$

The deteriorating cost in Own Warehouse for the developed model is denoted as $\mathrm{DC}_{\mathrm{Ow}}$ and defined is

$$
D C_{\text {OW }}=C_{d}\left(\int_{t_{1}}^{T} \beta(t) I_{O}(t) d t\right)=C_{d}\left(\beta_{1} v_{1}(t)+\beta_{2} v_{2}(t)-\left(\beta_{1}^{2}-\beta_{2}\right) v_{3}(t)-\frac{3 \beta_{1} \beta_{2}}{2} v_{4}(t)\right)
$$

The total inventory cost (TIC) per unit time is

$$
\operatorname{TIC}\left(t_{2}, t_{3}\right)=\frac{1}{T}\left[I O C+I H C_{R W}+I H C_{O W}+D C_{R W}+D C_{O W}\right]
$$

The total relevant inventory cost is minimum if $\frac{\partial T I C}{\partial t_{2}}=0, \frac{\partial T I C}{\partial t_{3}}=0$ and $\frac{\partial^{2} T I C}{\partial t_{1}^{2}}>0$.

\section{NUMERICAL EXAMPLE}

To demonstrate the above results for the developed model, we considered the example: $a=1100, b=0.5$, $c=0.05, \quad h(t)=0.07+0.007 t, \quad g(t)=0.06+0.006 t, \quad \alpha(t)=0.06+0.006 t, \beta(t) 0.05+0.005 t, \quad \mathrm{C}_{0}=1200, \quad \mathrm{C}_{\mathrm{d}}=0.05 \quad$ and $t_{1}{ }^{*}=0.18$ (year). The total inventory cost (TIC) is minimum when $t_{2}{ }^{*}=0.24, t_{3}{ }^{*}=4.4$, optimal order quantity is $\mathrm{L}^{*}=5946$ and the total minimum inventory cost $\mathrm{TIC}^{*}=455$.

\section{CONCLUSION}

In this paper, an attempt has been through to solving this mathematical model with two warehouses. Due to seasonal product, the storing of product/items is very essential for minimizing the total inventory cost. For developing this paper we consider some important parameters like quadratic demand, variable holding cost and variable deteriorating cost under the two warehouse management system, which has not yet been discussed. The model explained in this study tends to improve the optimal order quantity and total minimizing cost for manufacturing and retailing industries. For future research, it would be interesting to study the inventory models with probabilistic and stochastic, production, inflation and partial backlogging etc can be taken forward.

\section{ACKNOWLEDGMENT}

The authors would like to thank the Editor-in-chief of the journal and Reviewer for their support and beneficial comments to improvement of the paper. The authors would like to express their heartiest gratitude to Dr. P.S. Bhatnagar, Director, B.K. Birla Institute of Engineering \& Technology Pilani, Rajasthan (India).

\section{REFERENCES}

[1] Ghare, P.M. Schrader, G.P. (1963). A model for an exponentially decaying inventory. Journal of Industrial Engineering. 14, 5, 238243.

[2] Covert, R.P. and Philip, G.P., (1973). An EOQ model for items with Weibull distribution deterioration, AIIE Trans., 5(4), 323-329.

[3] Hertely V. Ronald., (1976). On the EOQ model two levels of storage. Opsearch, 13, 190-196.

[4] Pakkala, T. and Acharya, K. (1992). A deterministic inventory model for deteriorating items with two warehouses and finite replenishment rate, European J. Oper. Res., 57, 71-76.

[5] Lee, C. and Ma, C. (2000). Optimal inventory policy for deteriorating items with two-warehouse and time-dependent demands, Prod. Plan. and Cont., 11, 689-696.

[6] Kharna S. and Chaudhuri K.S., (2003). A note on order level inventory model for a deteriorating item with time dependent quadratic demand, Comp. and Ops Res., 30, 1901-1916. 
[7] Yang, H. (2004). Two-warehouse inventory models for deteriorating items with shortage under inflation, European J. Oper. Res., 157, 344-356.

[8] Malik, A. K., Singh, S. R. and Gupta, C. B. (2008). An inventory model for deteriorating items under FIFO dispatching policy with two warehouse and time dependent demand, Ganita Sandesh Vol. 22, No. 1, 47-62.

[9] Niu, B. and Xie, J. (2008). A note on two-warehouse inventory model with deterioration under FIFO dispatch policy, European J. Oper. Res., 190, 571-577.

[10] Lee, C.C. and Hsu, S. L., (2009). A two-warehouse production model for deteriorating inventory items with time-dependent demands, European Journal of Operational Research, 194, 700-710.

[11] Singh, S.R., Malik, A.K., (2009). Effect of inflation on two warehouse production inventory systems with exponential demand and variable deterioration, International Journal of Mathematical and Applications, 2, (1-2), 141-149.

[12] Malik, A. K., Singh, S. R. and Gupta, C. B. (2009).Two warehouse inventory model with exponential demand and time-dependent backlogging rate for deteriorating items, Ganita Sandesh Vol. 23, No. 2, 121-130.

[13] Singh, S.R., Malik, A.K., (2009).Two warehouses model with inflation induced demand under the credit period, International Journal of Applied Mathematical Analysis and Applications, Vol. 4, No.1, 59-70.

[14] Sarkar, S., Sana, S.S. and Chaudhuri, K. (2010). A finite replenishment model with increasing demand under inflation, Int. J. Math. Oper. Res., 2(3), 347-385.

[15] Gupta, C. B., Malik, A. K. and Singh, S. R. (2010). A Two Warehouse Inventory Model for Deteriorating Items with Demand Dependent Production, Ganita Sandesh, Vol. 24, No. 1, 55-62.

[16] Singh, S.R., Malik, A.K., (2010). Inventory system for decaying items with variable holding cost and two shops, International Journal of Mathematical Sciences, Vol. 9, No. 3-4, 489-511.

[17] Sana, S.S. (2010). Optimal selling price and lot size with time varying deterioration and partial backlogging, Appl. Math. Comput., 217, 185-194.

[18] Singh, S.R. and Malik, A.K. (2010). Optimal ordering policy with linear deterioration, exponential demand and two storage capacity, Int. J. Math. Sci., 9(3-4), 513-528.

[19] Singh, S.R., Malik, A.K., and Gupta, S. K. (2011). Two Warehouses Inventory Model with Partial Backordering and Multi-Variate Demand under Inflation, International Journal of Operations Research and Optimization, Vol. 2, No. 2, 371-384.

[20] Singh, S.R., Malik, A.K., and Gupta, S. K. (2011). Two Warehouses Inventory Model for Non-Instantaneous Deteriorating Items With Stock-Dependent Demand, International Transactions in Applied Sciences, Vol. 3, No. 4, 749-760.

[21] Seth, B. K., Sarkar, B., Goswami A., (2012). A two-warehouse inventory model with increasing demand and time varying deterioration. Scientia Iranica, E 19, 1969-1977.

[22] Kumar Aadarsh, Singh Amardeep, Bansal Kapil Kumar (2016) Two warehouse inventory model with ramp type demand, shortages under inflationary environment, IOSR Journal of Mathematics (IOSR-JM), 12(3), 06-17.

[23] Vashisth, V., Soni, R., Jakhar, R., Sihag, D., and Malik, A. K. (2016). A Two Warehouse Inventory Model with Quadratic Decreasing Demand and Time Dependent Holding Cost, AIP Conference Proceedings 1715, 020066; doi: 10.1063/1.4942748.

[24] Sharma, M. K. and Bansal K. K., (2017). Inventory Model for Non-Instantaneous Decaying Items with Learning Effect under Partial Backlogging and Inflation, Global Journal of Pure and Applied Mathematics,13(6), 1999-2008.

\section{Appendices}

$$
\begin{aligned}
& u_{1}(t)=-a t_{2}\left(t_{1}-t_{2}\right)+a_{1}\left(\frac{\left(t_{1}+t_{2}\right)^{3}-t_{1}^{3}-3 t_{2}^{3}}{3}\right)+a_{2}\left(\frac{\left(t_{1}+t_{2}\right)^{4}-t_{1}^{4}-4 t_{2}^{4}}{4}\right)+a_{3}\left(\frac{\left(t_{1}+t_{2}\right)^{5}-t_{1}^{5}-5 t_{2}^{5}}{5}\right)+a_{4}\left(\frac{\left(t_{1}+t_{2}\right)^{6}-t_{1}^{6}-6 t_{2}^{6}}{6}\right) \\
& u_{2}(t)=\left(a t_{2}-a_{1} t_{2}^{2}-a_{2} t_{2}^{3}-a_{3} t_{2}^{4}-a_{4} t_{2}^{5}\right)\left(\frac{\left(t_{1}+t_{2}\right)^{4}-t_{1}^{4}}{4}\right)-a\left(\frac{\left(t_{1}+t_{2}\right)^{5}-t_{1}^{5}}{5}\right) \\
& +a_{1}\left(\frac{\left(t_{1}+t_{2}\right)^{6}-t_{1}^{6}}{6}\right)+a_{2}\left(\frac{\left(t_{1}+t_{2}\right)^{7}-t_{1}^{7}}{7}\right)+a_{3}\left(\frac{\left(t_{1}+t_{2}\right)^{8}-t_{1}^{8}}{8}\right)+a_{4}\left(\frac{\left(t_{1}+t_{2}\right)^{9}-t_{1}^{9}}{9}\right) \\
& u_{3}(t)=\left(a t_{2}^{2}-a_{1} t_{2}^{3}-a_{2} t_{2}^{4}-a_{3} t_{2}^{5}-a_{4} t_{2}^{6}\right)\left(\frac{t_{2}+2 t_{1}}{2}\right)-a\left(\frac{\left(t_{1}+t_{2}\right)^{3}-t_{1}^{3}}{3}\right) \\
& +a_{1}\left(\frac{\left(t_{1}+t_{2}\right)^{4}-t_{1}^{4}}{4}\right)+a_{2}\left(\frac{\left(t_{1}+t_{2}\right)^{5}-t_{1}^{5}}{5}\right)+a_{3}\left(\frac{\left(t_{1}+t_{2}\right)^{6}-t_{1}^{6}}{6}\right)+a_{4}\left(\frac{\left(t_{1}+t_{2}\right)^{7}-t_{1}^{7}}{7}\right) \\
& u_{4}(t)=\left(a t_{2}-a_{1} t_{2}^{2}-a_{2} t_{2}^{3}-a_{3} t_{2}^{4}-a_{4} t_{2}^{5}\right)\left(\frac{\left(t_{1}+t_{2}\right)^{3}-t_{1}^{3}}{3}\right)-a\left(\frac{\left(t_{1}+t_{2}\right)^{4}-t_{1}^{4}}{4}\right) \\
& +a_{1}\left(\frac{\left(t_{1}+t_{2}\right)^{5}-t_{1}^{5}}{5}\right)+a_{2}\left(\frac{\left(t_{1}+t_{2}\right)^{6}-t_{1}^{6}}{6}\right)+a_{3}\left(\frac{\left(t_{1}+t_{2}\right)^{7}-t_{1}^{7}}{7}\right)+a_{4}\left(\frac{\left(t_{1}+t_{2}\right)^{8}-t_{1}^{8}}{8}\right) \\
& u_{5}(t)=S t_{1}-\left(\frac{a t_{1}^{2}}{2}-\frac{b t_{1}^{3}}{6}-\frac{c t_{1}^{4}}{12}\right), \quad u_{6}(t)=\frac{S t_{1}^{2}}{2}-\left(\frac{a t_{1}^{3}}{3}-\frac{b t_{1}^{4}}{8}-\frac{c t_{1}^{5}}{15}\right)
\end{aligned}
$$




$$
\begin{aligned}
v_{1}(t)= & S\left\{t_{2}-\frac{\beta_{1} t_{2}^{2}}{2}-\beta_{2}\left(\frac{t_{2}^{3}}{3}+t_{1} t_{2}\right)\right\}-b\left(T\left(t_{1}+t_{2}\right)-\frac{\left(t_{1}+t_{2}\right)^{2}}{2}-\frac{T^{2}}{2}\right)+b_{1}\left(T^{2}\left(t_{1}+t_{2}\right)-\frac{2 T^{3}}{3}-\frac{\left(t_{1}+t_{2}\right)^{3}}{3}\right) \\
& +b_{2}\left(T^{3}\left(t_{1}+t_{2}\right)-\frac{3 T^{4}}{4}-\frac{\left(t_{1}+t_{2}\right)^{4}}{4}\right)+b_{3}\left(T^{4}\left(t_{1}+t_{2}\right)-\frac{4 T^{5}}{5}-\frac{\left(t_{1}+t_{2}\right)^{5}}{5}\right)+b_{4}\left(T^{5}\left(t_{1}+t_{2}\right)-\frac{5 T^{6}}{6}-\frac{\left(t_{1}+t_{2}\right)^{6}}{6}\right) \\
v_{2}(t)= & S\left\{t_{2}\left(t_{1}+\frac{t_{2}}{2}\right)-\beta_{1}\left(\frac{t_{2}^{3}}{3}+\frac{t_{1} t_{2}^{2}}{2}\right)-\frac{\beta_{2}}{2}\left(t_{1}^{2} t_{2}^{2}+\frac{t_{2}^{4}}{4}+t_{1} t_{2}^{3}\right)\right\} \\
& -\frac{\beta_{2}}{2}\left\{\left(\left(b T-b_{1} T^{2}-b_{2} T^{3}-b_{3} T^{4}-b_{4} T^{5}\right)\left(\frac{\left(t_{1}+t_{2}\right)^{4}}{4}\right)\right)+b\left(\frac{4\left(t_{1}+t_{2}\right)^{5}+T^{5}}{20}\right)-b_{1}\left(\frac{2\left(t_{1}+t_{2}\right)^{6}+T^{6}}{12}\right)\right\} \\
-b_{2}\left(\frac{8\left(t_{1}+t_{2}\right)^{7}+21 T^{7}}{56}\right)-b_{3}\left(\frac{\left(t_{1}+t_{2}\right)^{8}+T^{8}}{8}\right)-b_{4}\left(\frac{4\left(t_{1}+t_{2}\right)^{9}+5 T^{9}}{36}\right) & \\
v_{3}(t)= & \left.-b T+b_{1} T^{2}+b_{2} T^{3}+b_{3} T^{4}+b_{4} T^{5}\right)\left(\frac{\left(t_{1}+t_{2}\right)^{2}}{2}\right)+b\left(\frac{2\left(t_{1}+t_{2}\right)^{3}+T^{3}}{6}\right) \\
& -b_{1}\left(\frac{\left(t_{1}+t_{2}\right)^{4}+T^{4}}{4}\right)-b_{2}\left(\frac{2\left(t_{1}+t_{2}\right)^{5}+T^{5}}{10}\right)-b_{3}\left(\frac{\left(t_{1}+t_{2}\right)^{6}+2 T^{6}}{6}\right)-b_{4}\left(\frac{2\left(t_{1}+t_{2}\right)^{7}+5 T^{7}}{14}\right) \\
v_{4}(t)= & \left.-b T+b_{1} T^{2}+b_{2} T^{3}+b_{3} T^{4}+b_{4} T^{5}\right)\left(\frac{\left(t_{1}+t_{2}\right)^{3}}{3}\right)+b\left(\frac{3\left(t_{1}+t_{2}\right)^{4}+T^{4}}{12}\right) \\
& -b_{1}\left(\frac{3\left(t_{1}+t_{2}\right)^{5}+2 T^{5}}{15}\right)-b_{2}\left(\frac{\left(t_{1}+t_{2}\right)^{6}+T^{6}}{6}\right)-b_{3}\left(\frac{3\left(t_{1}+t_{2}\right)^{7}+4 T^{7}}{21}\right)-b_{4}\left(\frac{3\left(t_{1}+t_{2}\right)^{8}+5 T^{8}}{24}\right) \\
v_{5}(t)= & S t_{1}, v_{6}(t)=\frac{S t_{1}^{2}}{2}
\end{aligned}
$$

